Economic and Environmental Geology

Review

\title{
A Monitoring Strategy on Dispersion of Particulate Matter emitted from Domestic Limestone Open Pit Mines
}

\author{
Jinho Yoon ${ }^{1}$, Sang-hun Lee ${ }^{1, *}$, Eui Young Seo ${ }^{2}$, Seunghan Baek ${ }^{2}$ \\ ${ }^{1}$ Department of Environmental Science, Keimyung University, 1095 Dalgubeol-daero, Daegu, 42601, Republic of Korea \\ ${ }^{2}$ Institute of Mine Reclamation Research, Mine Reclamation Corporation, Wonju, Republic of Korea \\ *Corresponding author : shlee73@kmu.ac.kr
}

\section{ARTICLE INFORMATION}

Manuscript received 18 August 2021

Received in revised form 27 August 2021

Manuscript accepted 27 August 2021

Available online 31 August 2021

DOI : http://dx.doi.org/10.9719/EEG.2021.54.4.475

\section{Research Highlights}

- An effective monitoing strategy on mine PM dispersion was provided as well as the relevant literature review.

- A preliminary operation of PM monitoring was provided with multiple low-cost PM sensors and LTE communication for this study.

- The effective modeling of mine PM dispersion should include PM size-dependant terms in the model equations.

\begin{abstract}
This study proposed a strategy with literature review on effective monitoring of dispersion of the particulate matters (PM) emitted from domestic open pit lime mines. The mines generally produced a large amount of PM through the mine processes such as crushing and transportation of raw or crushed ores. The PM emission from mine facilities or transportation can be assessed using empirical equations which was prepared through the experimental tests to produce PM from ores. For effective monitoring of mine PM dispersion, this study showed a preliminary application of the monitoring network with multiple low-cost sensors around a main PM emission source for each mine site. Therefore, two domestic limestone mine sites were selected for this study, and install the monitoring network with low-cost PM sensors and LTE (Long-term evolution) data communication. Then, preliminary resultant PM data plotted according to monitoring duration showed typical PM dispersion patterns. The quantification of the PM dispersion patterns should be roughly prepared by a PM size-dependent dispersion modeling.
\end{abstract}

Keywords : particulate matter (PM), dispersion, monitoring, low-cost sensor, mine

Citation: Yoon, J., Lee, S.-h., Seo, E.Y., Baek, S. (2021) A Monitoring Strategy on Dispersion of Particulate Matter emitted from Domestic Limestone Open Pit Mines. Korea Economic and Environmental Geology, v.54, p.475-482, doi:10.9719/EEG2021.54.4.475.

This is an Open Access article distributed under the terms of the Creative Commons Attribution Non-Commercial License (http://creativecommons.org/ licenses/by-nc/3.0) which permits unrestricted non-commercial use, distribution, and reproduction in any medium, provided original work is properly cited. pISSN 1225-7281; eISSN 2288-7962/@2021 The KSEEG. Printed by Hanrimwon Publishing Company. All rights reserved. 


\title{
해설
}

\section{국내 노천 석회석 광산먼지 확산 모니터링 방안}

\author{
윤진호 $^{1} \cdot$ 이상훈 ${ }^{1, *} \cdot$ 서의영 ${ }^{2} \cdot$ 백승한 $^{2}$
}

${ }^{1}$ 계명대학교 환경학부, ${ }^{2}$ 한국광해관리공단

*책임저자 : shlee73@kmu.ac.kr

\section{요 약}

본 연구에서는 국내 석회석 노천 광산시설이나 현장에서 배출되는 광산 미세먼지의 특징과 이를 효과적으로 모니터링 할 수 있 는 방안에 대해 관련 문헌 검토 및 전략을 제시하였다. 광산에서는 채굴된 광석의 파쇄와 운송 등의 공정에서 많은 양의 광산 먼지들이 발생한다. 광석에서 인위적으로 광산먼지를 생성시키는 실험를 통해 제시된 배출계수 및 관련 경험식으로 광산 시설 또는 운송 과정에서의 PM 배출량을 추정할 수 있다. 광산 PM 분산의 효과적인 모니터링을 위해 본 연구는 광산 현장의 주요 $\mathrm{PM}$ 배출원 주변에 여러 개의 저가 센서를 갖춘 모니터링 네트워크를 적용하였다. 따라서 본 연구에서는 시범적으로 국내 2곳 의 석회석 광산 현장을 선정하여 저가의 PM 센서와 LTE(Long-Term Evolution) 데이터 통신을 통한 모니터링 네트워크를 설치 하였다. 모니터링 예비 운전 결과 모니터링 기간에 따 PM 데이터는 통상적인 PM 분산 패턴을 보여주었다. 먼지 입도를 감안 한 확산모델링을 PM 분산 패턴을 대략적으로 정량화할 수 있다. 또한 먼지 확산 추정을 위해서는 현장의 기상 및 지형 조건 이 외에도 먼지 입도에 따른 거동을 반영한 확산 모델식을 이용하여야 한다.

주요어 : (미세)먼지, 확산, 모니터링, 저가센서, 광산

\section{1. 서 론}

석회석 광산활동(탐사 및 광산 생산 시추, 채광 및 선 광 등)에서 다양한 환경오염물질이 배출될 수 있는데 이 중 가장 대표적인 것이 광산먼지이다 (Sairanen et al., 2018). 예를 들어 채굴된 광석은 파분쇄 등의 공정을 거 칠 때 많은 양의 먼지파편들이 생성될 수 있다. 이 중 대 략 직경 50-60 $\mu \mathrm{m}$ 이하의 먼지는 총 먼지 (TSP: Total Suspended Particles)로 간주되며, 이들은 대기 중에 부유 하면서 광산환경 및 작업자와 인근 주민들의 건강을 악 화시킬 수 있다(Petavratzi et al., 2005). 이들 먼지 중 특 히 입경 $10 \mu \mathrm{m}$ 이하의 미세먼지 $\left(\mathrm{PM}_{10}\right)$ 나 $2.5 \mu \mathrm{m}$ 이하의 초미세먼지 $\left(\mathrm{PM}_{2.5}\right)$ 는 공기 중에 오래 지속적으로 부유하 며 인체에 쉽게 침투하여 광산 및 인근지역의 대기환경 을 장기간 악화시킬 수 있다. 이러한 먼지가 광산 근로 자에 빈번히 노출되면 호흡기를 비롯한 눈이나 피부에 침투하여 암을 비롯한 다양한 질병을 유발시킬 수 있다 (WHO, 1999). 광산 근로자의 분진노출을 제한하기 위한 각종 규정이나 방지시설 같은 법적/기술적 조치에도 불 구하고, 광산에서의 먼지 배출 문제는 여전히 문제로 인 식되고 있다. 또한, 광산외부로 배출된 미세먼지는 장기 간 부유가 가능하여 종종 발생원(광산)에서 멀리 떨어진 장소까지 이동하기도 한다. 이로 인해 광산인근 지역의
주민건강이나 농업 및 생태환경에도 악영향을 끼칠 수 있다 (Petavratzi et al., 2005).

이러한 광산먼지 특히 미세먼지 문제에 효과적으로 접근 하고 나아가 합리적인 해결책을 제시하기 위해서는 광산먼 지의 특성, 기기분석, 발생원 규명, 확산 및 이송, 감시 모 니터링, 방지대책 등 다양한 측면에서의 폭넓은 이해가 바 탕이 되어야 한다. 이는 내용이 매우 방대하고 다양한 원리 를 배경으로 한다. 따라서 본 연구에서는 일단 광산먼지의 발생과 이송특성, 연속자동 모니터링 관련 기존 연구를 정 리하고 검토하는데 중점을 두었다. 추가적으로 본 연구에 서 국내 석회석 광산을 대상으로 저가 센서 모니터링 시 스템을 설치하고 예비 운전 수행 결과를 간략히 소개하였다.

\section{2. 석회석 광산먼지 배출}

노천 석회석 광산 에서 생성되는 분진은 부지 준비, 시 추, 발파, 채석 등 건설 공사나 비축, 적재, 운송 및 처리 같은 광산운영 등 다양한 작업에서 발생할 수 있다. 광 석 처리 및 취급공정 이외에 광산 사업장내 혹은 인근 비포장 도로를 운행하는 트럭 등 운송장비로 인해 먼지 가 생성될 수 있다 (John et al., 2004). 이러한 먼지는 광 산먼지의 주요 배출원 중 하나로 도로에 침적된 먼지가 트럭 등에 의해서 재부유되는 식으로 인해 대기질을 오 
염시키는 경우가 흔하다. Petavratzi et al., (2005)의 연구 에서 영국 District National Prak 의 Buxton 근처에 위치 한 대규모 채석장 및 작업단지에서 측정을 하였는데, 평 가를 위한 실측항목에는 $\mathrm{PM}_{10}$ 질량, 입자 크기 분포, 풍 속 및 풍향이 포함되었다. 실측 결과 트럭에 의한 광산 인근 도로 먼지 재부유에 의해 해당 구역내 $\mathrm{PM}_{10}$ 농도 가 $630 \mathrm{~g} / \mathrm{m}^{3}$ 까지 증가하였으며 상당 부분 조대먼지였다. 적재 트럭의 배출율이 $\mathrm{PM}_{10}$ 배출률이 $6,108 \mathrm{mg} / \mathrm{km}$ 로 산 정되었다. 이러한 먼지는 미세하거나 석영과 같은 물질 이 포함되어 있을 경우 유해성을 띄므로 주의가 필요하 다(Petavratzi et al., 2005). 특히 주거지역이나 인구밀도 가 높은 지역이 광산현장인근에 위치할 경우 민원발생 등 문제시 될 소지가 높아 보건 및 대기질 측면에서 더 세심한 관리가 필요하다. 전술한 대로, 광산에서는 파쇄 및 Sieving 공정과 운반 중에 에서 가장 많은 분진이 발 생되는 것으로 알려져 있는데, 이 때 형성된 먼지는 일 반적으로 주요 발생원에 덮개를 씨우거나 물 세정 등으 로 제어된다(Sairanen et al., 2018). 또한 이에 앞서 다양 한 광산작업과 광물취급/처리공정 그리고 이송 중에 암 석이나 광물이 먼지로 변하는 과정을 이해할 필요가 있 다. 먼지는 크게 생성과 배출 단계를 통해 대기 중에 발 생되며, 이 중 먼지 생성을 유도하는 물리적 힘에는 암 석 또는 광물의 충격, 마모 또는 파쇄력 등이 포함된다. 또한 이러한 힘에 관련된 인자로는 광석의 경도, 입도분 포, 밀도 및 수분과 같은 재질특성과 공정소비 에너지, 낙하 높이, 처리량 및 취급 범위 등 공정인자가 있다. 이 렇게 먼지생성단계 이후 생성먼지의 일부가 외부 혹은 대기로 배출된다(Petavratzi et al., 2005).

광석의 먼지생성도는 직접적으로 실측을 통해 평가할 수 있다. 일례로 회전 드럼을 통하여, 인위적으로 석회석 광석에서 먼지를 생성시킬 수 있는데,측정기내에 회전드 럼을 장착하여 광석이 Rolling되면서 먼지가 생성된다 (Lyons and Mark, 1994; Schneider and Hjemsted, 1996). 물론 측정기 혹은 측정방식에 따라 충격, 낙하, 유동화 등 먼지생성에 관련된 다양한 형태의 힘을 광석에 가할 수 있다(BOHSTC, 1985 ; Higman, 1985; Lyons and Mark, 1994; Schneider and Hjemsted, 1996).

또 다른 MRI (Magnetic Resonance Imaging) 먼지 검 사와 DPA (Dust Paticle Apparatus) 먼지 입자 장치 같은 경우 Dumping에 의해 생성된 입자를 부유시킨 후 여과 채집하는 방식을 적용한다(Sethi and Schneider, 1996). 석 회암 표본의 먼지를 지배하는 가장 중요한 인자는 보통 테스트 대상 광석표면에 분포한 먼지 농도와 텀블링 시 간 등이 있다. 또한 측정기 내 드럼을 통해 유입되는 공 기 흐름 속도가 증가함에 따라 생성먼지 부하도 증가하
는 것으로 나타났다 (Petavratzi et al., 2007). 상기와 같 은 측정기를 통해 석회석에서의 먼지배출량을 실측하며 이와 관련된 배출계수를 산정할 수 있다 (Petavratzi et $a l .$, 2007). 즉 광석 등에서의 먼지생성량 추정은 측정기 를 통해 실측 할 수도 있고 기존 실측치를 통해 결정된 배출 계수를 이용할 수 있다(US EPA, 2014). 다양한 기 관에서 배출 인자 (Aatos, 2003; Chang el al, 2010; Chakraborty et al., 2004 Sairanen et al., 2018)를 추정하 였는데, 이 중 미국 $\mathrm{EPA}$ 배출 인자가 가장 보편적으로 활용된다(US EPA, 2014).

원석의 loading과 unloading 작업에서의 $\mathrm{PM}_{10}$ 배출 계 수는 각각 $8.0 \times 10^{-6} \mathrm{~kg} / \mathrm{t}$ (US EPA et al., 2015)와 0.48 $\mathrm{kg} / \mathrm{t}$ 로 산정되었다(Chang et al., 2010). 파쇄 광석의 경우 $\mathrm{PM}_{10}$ 배출 인자는 $5.0 \times 10^{-5} \mathrm{~kg} / \mathrm{t}$ (US EPA et al., 2015) 및 $0.56 \mathrm{~kg} / \mathrm{t}$ 이었다(Chang et al., 2010). 입상체(Gravel) 처리공정에서의 먼지 배출 인자는 미국 $\mathrm{EPA}$ 배출 인자 에 비해 상당히 높은 수준(수만 배)이었다(Sairanen et al., 2018). 또한 $\mathrm{TSP} / \mathrm{PM}_{10}$ 의 비율도 차이를 보였는데 (Chang et al., 2010) 에서 보고된 배출인자로 계산할 때 TSP/ $\mathrm{PM}_{10}$ 비율 $1.4 \sim 1.7$ 인 반면, US EPA 배출계수를 이용하 면 1.7 4.1으로 산정되었다(Sairnen et al., 2018).

참고로 $\mathrm{EPA}$ (2015)에서 제시한 배출계수는 여러 문헌 을 리뷰한 결과를 종합하여 산정한 결과이며 Chang et al. (2010)의 경우에는 Taiwan내 Gravel processing 현장 을 고려한 결과이다.

또한 Abu-Allaban의 연구(2006)에서 제시한 움직이는 차량에서의 먼지배출계수는 다음 의 공식을 통해 산정된다.

$$
E_{m} F_{V}=\text { Area } \cdot C_{p m} \cdot V_{i} / V_{v}
$$

여기서 $\mathrm{E}_{\mathrm{m}} \mathrm{F}_{\mathrm{v}}$ 는 차량 주행 킬로미터 당 방출 된 먼지 중량 (Gram per moving distance of the vehichle in moving-km), Area는 Plume 면적 $\left(\mathrm{m}^{2}\right), \mathrm{C}_{\mathrm{pm}}$ 는 측정된 $\mathrm{PM}$ 농도 $\left(\mathrm{mg} / \mathrm{m}^{3}\right), \mathrm{V}_{\mathrm{i}}$ 는 풍속 $(\mathrm{m} / \mathrm{s}), \mathrm{V}_{\mathrm{v}}$ 는 차량 속도 $(\mathrm{m} / \mathrm{s})$ 를 나타낸다. 또는 편의상 $\mathrm{E}_{\mathrm{m}} \mathrm{F}_{\mathrm{v}}$ 를 다음과 같이 보다 간단히 표현할 수도 있다(Abu-Allaban et al., 2006).

$$
E_{m} F_{V}=H_{V} \cdot t \cdot V_{i} \cdot C_{p m}
$$

여기서 $\mathrm{t}$ 는 노출 시간(s), 즉 연속된 두 차량 사이의 시 간 간격을 의미한다. 그리고 $\mathrm{H}_{\mathrm{V}}$ 는 차량 높이(m)을 나타 낸다(Abu-Allaban et al., 2006).

\section{3. 먼지확산 모니터링}

\section{1. 모니터링망 구축}

일반적으로 점오염원에서 연속배출되는 먼지만을 모니 
터링하려면 해당 배출지점에 측정기를 설치하여 모니터 링을 하면 되지만 노천광산 혹은 채석장 같이 노천광산 같이 주 오염원에서의 먼지배출량 변동이 심하고 먼지확 산이 광활하게 이루어지는 경우, 다수의 고정상 먼지측 정기를 포함한 모니터링망(Monitoring network)을 구축하 여 먼지확산을 모니터링하는 것이 바람직하다. 전체 모니 터링 대상 지역내 개별 먼지측정기 위치는 주요 점오염원 바로 인근에 1 대 이상을 구축하여 여기서 측정된 결과로 실제 배출량을 용이하게 산정할 수 있다. 그리고 점오염원 을 중심으로 모니터링망을 방사상으로 구축하여 주요 점오 염원으로부터의 거리에 따른 먼지 확산 거동을 관측할 수 있다. 또한 가능하면 배출원에서 멀리 떨어진 민가 등도 모니터링하여 수용체(예를 들어 인근 거주민)에 흡수되는 먼지 중 광산배출원먼지의 기여도를 추정할 수 있다. (Page et al., 2000). 반면 먼지가 점오염원에서 집중적으로 발 생하는 것이 아니라 전체 대상 지역에서 고르게 발생된 다면 다른 망형태(예를 들면 전체 지역내 균등한 간격으 로 배치하는 직각좌표방식 등)를 고려해볼 수 있다(Chang et al., 2010). 또한 개별 먼지측정기의 위치는 주변에 높 은 구조물이나 나무에서 떨어진 지점에 설치하여 주변 구조물에 의하여 먼지 확산이 받는 영향을 가급적 최소 화하도록 해야한다(John et al., 2004, Chang et al., 2010).

구체적으로 본 연구에서는 국내의 석회석 광산 중 단 양과 횡성 지역내 운영중인 광산 2곳을 선택하였다. 각 광산현장내 주요 오염원 즉 먼지발생원(광석처리시설)을 중심으로 방사상 모양의 모니터링망을 Fig. 1과 같이 구 성하였다. 참고로 해당 광산현장내에는 석회석 채석, 처 리(파쇄), 하적 및 운반과정이 모두 포함되어 있다. 광산 인근지역은 인구밀도가 낮고 민가가 드문드문 위치하여 있다. 본 연구에서는 각 광산현장내 개별 모니터링기기 위치를 5 개 지점씩 선정하였다. 단양에 설치된 모니터링 위치(S01-S05로 명명)는 오염원인 S03을 기준으로 약 100 $\mathrm{m}$ 이상떨어져 있다. 한편 횡성의 경우 S06-S10은 오염원 인 S07과 S08 기준으로 약 $60 \sim 80 \mathrm{~m}$ 의 거리를 두고 설
치되어 있다. 상기 총 10 지점에 먼지 측정센서(DSM101, Radon FT Lab, Korea)를 설치하여 자동/원격 모니터링을 수행하였다, 참고로 상기 센서는 Laser Diode를 내장하 여 광산란 방식으로 $\mathrm{PM}_{1.0}, \mathrm{PM}_{2.5}, \mathrm{PM}_{10}$ 을 측정하며 후술 할 무선통신용 데이터로거(모뎀)와의 유선연결이 용이하 며 통신불량시를 대비하여 자체 저장기능도 가지고 있다.

먼지측정센서는 우천이나 파편 등으로 인한 악영향을 최소화하기 위해 간이백엽상내 설치하였다. 센서 구동에 필요한 전력은 가능한 광산내 가용전력을 이용하되, 그 렇지 못한 경우에는 태양전지를 이용하였다, 각 모니터 링 기기로부터의 데이터 통신기기은 광산현장 특성상 LTE (Long Term Evolution)모뎀을 간이백엽상 옆의 전원 장치내 설치하여 이용하였다. 참고로 WIFI나 일반 무선 통신은 현장 미설치 및 지형 등의 이유고 적용이 불가하 였다. 각 측정센서에서 생성된 먼지농도 데이터는 $\mathrm{TCP} /$ $\mathrm{IP}$ 방식으로 모뎀에서 사용자 $\mathrm{PC}$ 로 원격수신되었다. 현 장에 설치된 모니터링 기기(센서+간이백엽상+전원시스템 +모델+지지대)를 Fig. 2에 나타내었다. 이 후 모니터링망 의 예비 수행결과, 각 모니터링 지점에서의 측정결과를 일차적으로 Fig. 3의 그래프와 같이 시간대별로 도시할 수 있다. 모니터링 결과치를 보면 주 오염원 인근에 위 치한 센서의 PM 측정값이 매우 높았으며 센서 고유 최 대 측정값인 $4500 \mu \mathrm{g} / \mathrm{m}^{3}$ 을 넘는 경우도 빈번하였다. 반 면, 주 오염원에서 떨어진 곳에 위치한 센서의 측정값은 대부분 바탕치에 근접하였다(여기서 바탕치란 각 광산현 장에서 $10 \mathrm{~km}$ 이상 떨어진 곳에 위치한 기상대의 $\mathrm{PM}$ 농 도값을 의미한다.). 흥미로운 점은 기상대와 주 오염원에 서 떨어진 곳에 위치한 센서의 $\mathrm{PM}_{2.5}$ 측정치는 서로 유 사한 범위를 가지고 있지만 $\mathrm{PM}_{10}$ 의 경우에는 상대적으 로 차이가 있었다. 또한 기상대에서 측정된 먼지보다 광 산현장에서 측정된 먼지의 경우 $\mathrm{PM}_{10}$ 과 $\mathrm{PM}_{2.5}$ 간의 선형 적 상관관계가 훨씬 더 더 현저하였다. 이는 광산먼지의 $\mathrm{PM}_{10}$ 과 $\mathrm{PM}_{2.5}$ 의 연관성이 더 높다는 것을 의미하며 양자 간의 배출원 특성이 서로 유사함을 암시한다.

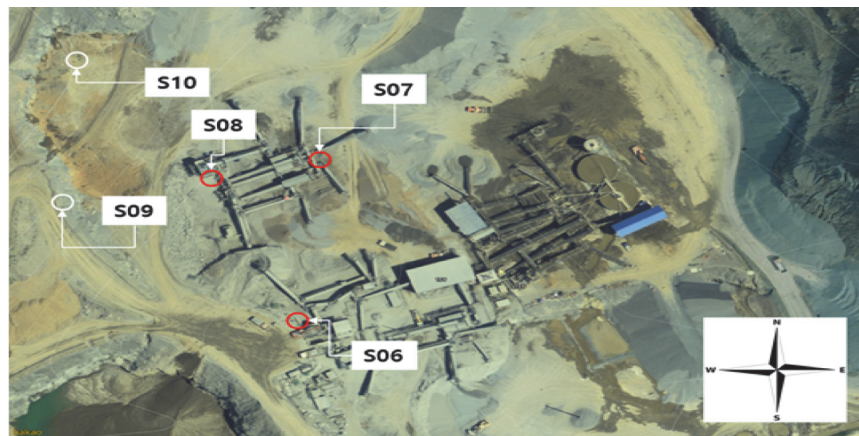

Fig. 1. The satellite images of the two limestone mine sites (Left and right images) for installation of monitoring networks in this study (citation - google map image), inlcuding the individual PM sensor locations from S01-S05 (Left) and S06-S10 (Right). 


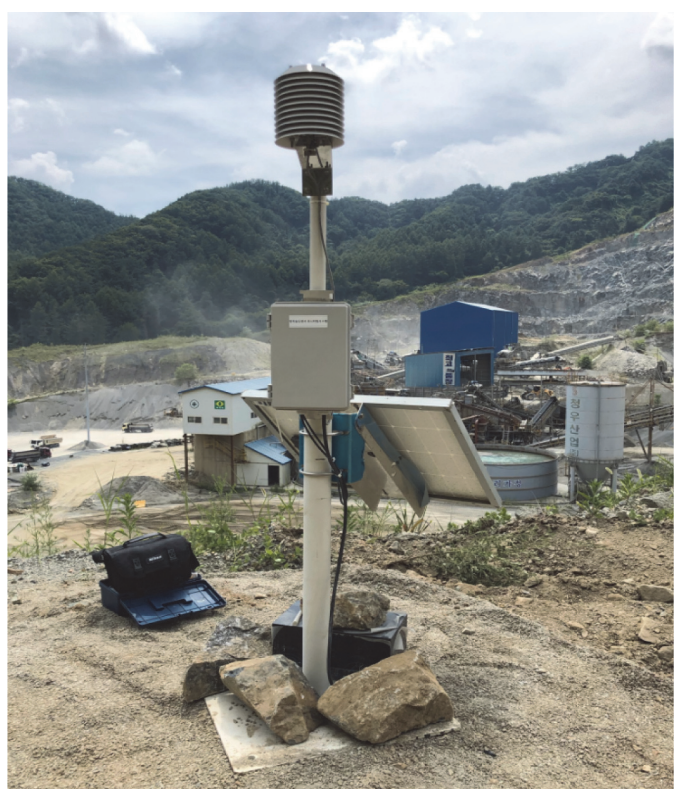

Fig. 2. Monitoring sensor installed in a limestone mine. (sensor + simple white leaf + power system + model + support $)$

\section{2. 기존연구에서 보고된 광산 먼지확산 거동}

기존 연구에서의 측정 결과를 보면 광산내 오염원 인 근에서의 총 먼지 농도는 $100-110,000 \mu \mathrm{g} / \mathrm{m}^{3}$ 의 넓은 범위를 보였다. 여기서 $\mathrm{PM}_{10}$ 농도는 총 먼지의 약 $25 \% \sim 50 \%$ 정도로 보고 되었으며 조대먼지는 주로 광물성 성분인 것으로 관측되었다. 먼지 확산 모니터링의 총 거리는 $10 \mathrm{~m}$ (Reed, 2003) 에서 9,000 m (Cattle et al., 2012) 까지 다 양했다. (Sairnen et al.,2018). 영국 부총리실에 따르면, 광석파쇄로 인해 발생된 먼지 중 입도 $30 \mu \mathrm{m}$ 이상은 $100 \mathrm{~m}$ 이내, 입도 10 30 $\mu \mathrm{m}$ 는 최대 200-500 $\mathrm{m}$ 까지 이동할 수 있으며 그 외 미세 입자 $(10 \mu \mathrm{m}$ 미만)는 더 멀리 오래 이
동하며 천천히 침적되는 것으로 보고되었다(IAQM, 2016). 입도 외에도 분진 확산거동 및 농도변화는 기상 조건 특 히 풍속과 풍향에 따라 크게 달라진다. 예를 들어 풍속 이 $1 \mathrm{~m} / \mathrm{s}$ 미만일 때, 먼지의 분산 및 희석효과는 미미하 다(Aatos, 2003; Sairnen et al., 2018; Sairanen et al., 2018). 반면 풍속이 유의미한 경우를 보면 Bluvshtein et al. (2011)의 연구에서는 건조한 여름철에 이스라엘 북부 에 위치한 석회석 채석장으로부터 Downwind 방향으로 약 $1 \mathrm{~km}$ 떨어진 지점의 누적 먼지량이 Upwind 대비 34배 더 많은 것으로 나타났다. 이는 풍속, 풍향이 먼지 확 산에 큰 영향을 미친다는 것을 보여준다. (Bluvshtein et al., 2011). 또한 광산 트럭 운행시 비포장도로에서도 먼 지가 발생하며 이 경우 먼지거동은 바람, 운행거리 및 도 로 조건 등에 영향을 받는다. 기존 연구에서 석회석 광 산 비포장 도로에서 $15.2 \mathrm{~m}$ 및 $30.5 \mathrm{~m}$ 떨어진 거리에서 먼지 농도를 측정한 결과 도로 옆에서 비산먼지가 고농 도로 발생하다가 측정지점 $30.5 \mathrm{~m}$ 근방에서 배경농도치 에 근접하게 급격히 감소하는 현상이 보고되었다(AbuAllaban et al., 2006).

\section{4. 먼지확산 모델링}

조사대상 지역내 임의의 시간대 혹은 위치에서의 농도 를 전부 모니터링 실측할 수는 없으므로 실측지점 이외 의 먼지 확산거동은 모델링을 통해 추정한다. 확산모델 링은 먼지 확산 거동 관련 다양한 메커니즘을 수식화하 여 먼지농도를 계산할 수 있다. 확산모델링 프로그램은 여러 종류가 있는데 먼지환경의 복잡성, 모델의 차수, 배 출원 특성, 계산 시간, 동적특성 및 농도의 정확성 등에 따라 각각 다르다(Holmes and Morawska, 2006; Sairanen

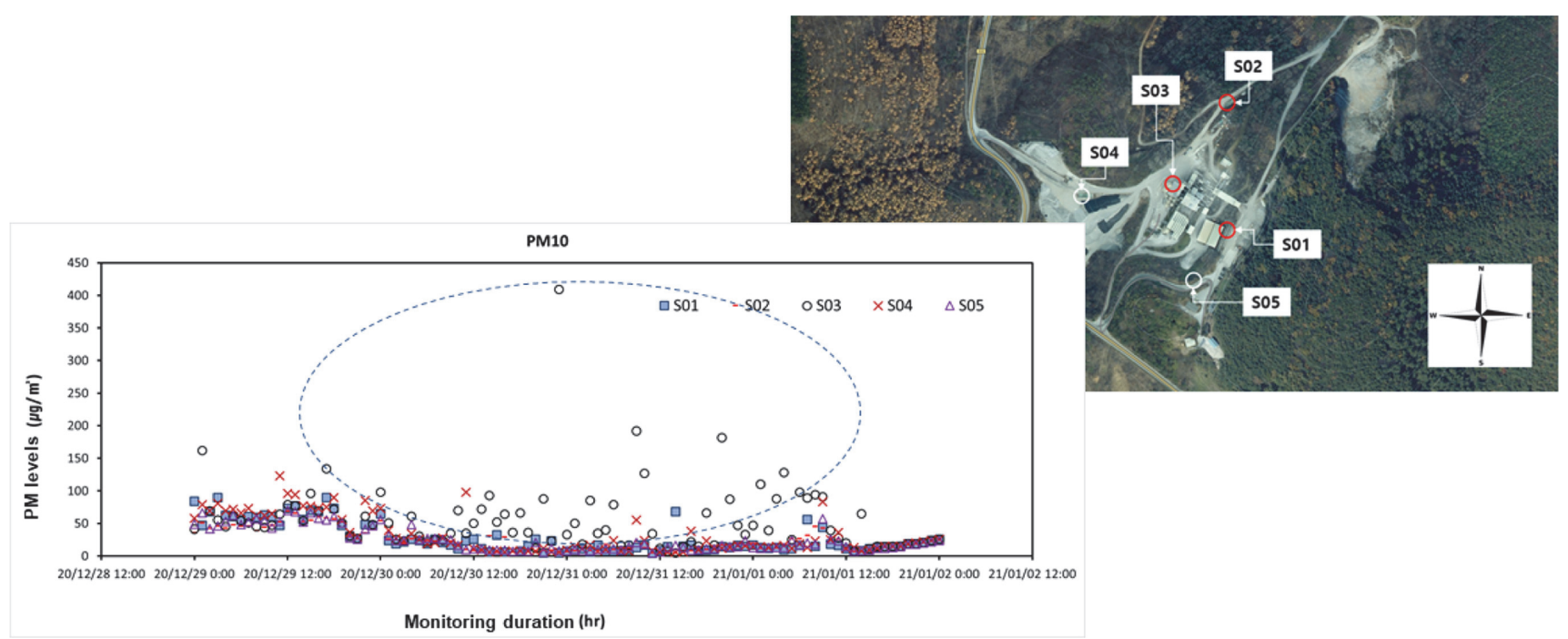

Fig. 3. Selective PM data from the each monitoring station of S01-S05. 
et al., 2018).

먼지분산 관련 수학적 모델의 개발과 활용은 일반 대 기질 관리 및 산업현장에서 필요하며, 그 중 일부는 광 산먼지 거동 예측이 목표이다. 일반적으로 Gaussian 기반 모델이 신속한 계산과 지형/기상 데이터와의 용이한 연 동으로 먼지 분산 시뮬레이션에 가장 적합한 것으로 알 려져 있다(Joseph et al., 2018). AERMOD (American Meteorological Society/Environmental Protection Agency Regulatory Model)는 이 Gaussain 기반 먼지분산을 모델 화할 수 있는 대표적인 프로그램이다. 이는 특별히 광산 용도로 설계된 것은 아니지만, 광산 분진 농도를 최대 50 $\mathrm{km}$ 까지 예측하는데 활용된다(Holmes and Morawska, 2006). 먼저 광산내 먼지 오염원으로부터 Cartesian 좌표 계상 $\mathrm{x}-\mathrm{y}-\mathrm{z}$ 방향으로의 먼지 난류분산은 $\mathrm{kx}, \mathrm{ky}, \mathrm{kz}$ 라는 확 산계수 $\left(\mathrm{m}^{2} / \mathrm{s}\right)$ 를 확산항에 포함시켜 모사된다. 여기에 $\mathrm{x}$ $\mathrm{y}-\mathrm{z}$ 방향으로의 풍속 $(\mathrm{m} / \mathrm{s}), \mathrm{v}_{\mathrm{x}}, \mathrm{v}_{\mathrm{y}}, \mathrm{v}_{\mathrm{z}}$ 를 통해 대류항을 구 성한다. 이를 통해 산출된 임의의 시간 $(\mathrm{t})$ 및 지점 $(\mathrm{x}, \mathrm{y}, \mathrm{z})$ 에서의 먼지농도는 다음 식(3)과 같이 나타낼 수 있다.

$$
\begin{gathered}
\frac{\partial c}{\partial t}=\frac{\partial}{\partial x}\left(k_{x} \frac{\partial c}{\partial x}\right)+\frac{\partial}{\partial y}\left(k_{y} \frac{\partial c}{\partial y}\right)+\frac{\partial}{\partial z}\left(k_{z} \frac{\partial c}{\partial z}\right) \\
-v_{x} \frac{\partial c}{\partial x}-v_{y} \frac{\partial c}{\partial y}-v_{z} \frac{\partial c}{\partial z}+S o-S i
\end{gathered}
$$

여기서 $\mathrm{c}$ 는 먼지농도 $\left(\mathrm{mg} / \mathrm{m}^{3}\right)$ 이고, $\mathrm{So}$ 와 $\mathrm{Si}$ 는 각각 해 당 시각 $(\mathrm{t})$ 및 지점 $(\mathrm{x}, \mathrm{y}, \mathrm{z}$,$) 에서의 먼지발생율 (\mathrm{mg} / \mathrm{s})$ 및 제 거율 $(\mathrm{mg} / \mathrm{s})$ 을 의미한다. 여기서 $\mathrm{So}=0, \mathrm{Si}=0$ 및 먼지 농도 가 시간에 따라 불변하는 정상상태 조건하에서, $\mathrm{x}$ 방향에 따른 바람만을 고려하고 $\left(\mathrm{v}_{\mathrm{x}}>0 . \mathrm{v}_{\mathrm{y}}=\mathrm{v}_{\mathrm{z}}=0\right), \mathrm{z}=\mathrm{h}$ 고도에서 의 먼지 배출원을 가정한다면 식(3)은 다음 식(4)와 같은 해석해를 갖는다.

$$
C \approx \frac{Q}{2 \pi v_{x} \sigma_{y} \sigma_{z}} e^{-\frac{y^{2}}{2 \sigma_{y}^{2}}}\left(e^{-\frac{(z-h)^{2}}{2 \sigma_{z}^{2}}}+e^{-\frac{(z+h)^{2}}{2 \sigma_{z}^{2}}}\right)
$$

여기서 $\mathrm{Q}$ 는 배출량 $(\mathrm{mg} / \mathrm{s}), \sigma_{\mathrm{y}}$ 와 $\sigma_{\mathrm{z}}$ 는 각각 $\mathrm{y}$ 와 $\mathrm{z}$ 방 향의 농도 편차(난류확산계수와 선형정비례 관계)를 의 미한다. 먼지 분산모델링을 위한 상기 초기 Gaussian 기 반 모델의 주요 단점은 입도 영향에 관련된 항이나 계수 가 없다는 점이다. 광산먼지는 입도에 따라 성상이 달라 지는데 (Lee, 2020) 예를 들어 조대먼지는 대체로 광산의 기계적 처리과정에서 배출되는 반면, 초미세먼지는 많은 경우 연소과정에서 배출된다. 따라서 광산먼지 확산모델 링에 먼지입도에 관련된 항이나 매개변수가 반드시 포함 되어야한다. 수정된 $\mathrm{AERMOD}$ 에서는 입자크기와 관련된 침적(Dry \& wet deposition) 및 Scavenging 관련 방정식
을 확산모델링에 연동되었다(US EPA, 2004).

또한 노천광산 같은 대기질 먼지모델링에서 중요한 점 은 배출원 위치 및 배출량 이외에도 현장 기상 조건과 광산, 인근 지형 데이터 그리고 무엇보다도 광산먼지의 입도에 관련된 인자를 모델에 포함시켜야 한다는 점이다. 이는 관련된 모든 요인이 먼지 분산에 큰 영향을 미치기 때문이다. Sairanen et al. (2018) 의 연구에서는 석회성 광산 중 채석장의 지형 및 풍향과 관련된 발생원의 위치 가 먼지 분산에 큰 영향을 미치는 것으로 확인되었다 (Appleton et al., 2006; Lowndes et al., 2008; Torno et al., 2011). 이러한 모델링은 먼지 배출 감소를 위한 방지장치 을 개발하는 데도 유용하다(Torno et al., 2011; Torano et al., 2009; Sairnen et al., 2018).

Chaulya et al. (2000)의 연구에서는 석회석 광산 먼지 가 인근 대기질에 미치는 영향을 예측하기 위해서 모델 링을 수행하였다. 모델에는 기상자료, 광산활동정보 및 먼지배출 계수, 기준 대기질 및 기검증된 모델 조건이 포 함되었다. 먼저 모델에 관련된 기상관련 실측치 및 매개 변수 데이터를 수집하였다. 이 자료로부터 먼지 침착조 건(풍속 $0.6 \mathrm{~m} / \mathrm{s}$ 미만)을 포함하는 안정성 등급이 포함된 다이어그램을 구축하였고, 또한 Turner 분류 체계(Hanna et al., 1982)를 사용하여 일종의 대기질 안정성 등급을 산정하였다. 먼지농도의 배경치는 Chaulya et al. (2000) 연구에서 미국 Virginia 주내에 위치한 석회석광산현장 인근에서 얻은 실측값으로 하였다(Chaulya et al., 2000). 이 때 기상자료, 광산활동정보 및 배출원에서의 먼지배 출량을 입력하고 $\mathrm{FDM}$ (Fugitive Dust Model)을 통해 먼 지 확산모델을 수행하고, 광산내부 및 인근 위치에서의 먼지 농도를 예측하였다. 산출된 먼지농도는 등치지도에 의해 도식화되었으며 이때 모델에 미지정된 위치에서의 농도값은 적절한 지구통계학기법을 통해 외삽하였다 (Chaulya et al., 2000).

모델링 결과에 따르면 광산 조대먼지의 주요 배출원은 광석운반시설과 처리시설이며 그 외에서의 배출원 영향 은 미미한 것으로 보고되었다. 광산활동에 인한 24시간 평균 총 먼지 농도는 광산내에서는 약 $360 \mu \mathrm{g} \mathrm{m}^{-3}$, 장외 에서는 $130 \mu \mathrm{g} \mathrm{m}^{-3}$ 미만일 것으로 예측되었다. 부또한 배 출원제어와 함께 현장 경계 인근에서 $40 \mathrm{~m}$ 폭의 그린벨 트 녹지대를 구축하면 광산의 먼지오염영향을 획기적으 로 저감할 수 있을 것으로 언급하였다. 이에 광산 주변 의 녹지대 관련 다양한 인자, 즉 나무 높이, 녹지대 폭, 배출원에서 수용체까지의 거리, 나무의 먼지여과효과, 먼 지침적속도 등에 대한 민감도 분석 및 평가와 녹지대 설 계에 모델링을 이용하였다(Chaulya et al., 2000).

광산먼지 모델링 관련 최근 연구결과 중 하나로 바람 
에 의한 광산내 침적먼지 비산 모델링을 들 수 있다. 이 는 바람의 풍향/풍속에 따라 수직/수평 침투 효과를 모델 화하여 이에 따른 먼지거동과 확산거동을 평가하였으며, 모델링 결과 바람 침투 각도와 확산 계수에 따라 $\mathrm{PM}_{10}$ 먼지의 억제 및 분산이 발생하는 것으로 나타났다. 또한, 노천광산 $\mathrm{PM}_{10}$ 먼지의 $30-60 \%$ 가 이러한 바람의 침투 효 과로 인해 유지되는 것으로 산정되었다(Sumanth et al. 2020). 한편 먼지의 시공간 분포 실측치를 기반으로 배출 원 기여도를 산정하는데도 별도의 모델링이 적용될 수 있다(Sumanth et al., 2020).

광산먼지 배출원 기여도 모델링 결과 광산먼지, 토양 먼지, 시멘트 먼지, 석탄 연소 차량, 및 2차 미세먼지(황 산염이나 질산염 등 다수의 배출원이 확인되었다. 이 중 총 $\mathrm{PM}_{2.5}$ 미세먼지에 대한 석회석광산(채석장) 먼지의 기 여도는 약 $6 \%$ 로 산정되었고 토양 먼지와 시멘트 먼지의 기여도는 각각 $13 \%$ 로 산정되었다. 기타 배출원은 차량 (23\%) 및 석탄연소시설(18\%) 등이 확인되었다 (Peng et $a l ., 2016)$. 광산먼지의 입도별 특성을 조사하여 먼지의 물리적 및 화학적 특성을 이해하는 데 도움이 될 수 있 다(Peng et al., 2016; Petavratzi et al., 2005).

\section{5. 결 론}

광산 등 다양한 오염원에서 배출되는 먼지는 여러 환 경 및 보건문제를 야기한다. 본 연구에서는 여러 오염원 중 특히 노천 석회석 광산에서 배출된 광산먼지 확산거 동의 모니터링 방안에 대하여 논하였다. 효과적인 먼지 확산 모니터링을 위해서는 (1) 광산내 고농도 먼지를 배 출하는 주 오염원 파악 (2) 모니터링망 구상 및 구축 (3) 먼지확산 예측 및 평가방안 등으로 구분될 수 있을 것이 다. 석회석 광산 등 채석장에서 분진을 많이 발생시키는 공정은 광석의 파쇄 및 Sieving 공정으로 볼 수 있는데, 채석공정 작동시간이 길어지면 더 많은 먼지를 방출하게 되며, 이는 광산 및 인근지역의 대기환경을 악화시킨다. 광석처리 작업에서 나오는 분진 중 일부는 입도가 매우 작아 보건 및 대기질 측면에서 세심한 관리가 필요할 수 도 있다 광산먼지의 확산은 풍속이나 풍향 등 기상조건 과 입도 등 입자의 특성에 큰 영향을 받는다. 효과적인 광산먼지 모니터링을 위해서는 광산내 점오염원을 중심 으로 다수의 저가 먼지센서를 구비한 고정상 모니터링망 을 이용하는 것이 바람직하다. 따라서 본 연구에서는 국 내 석회석 광산 현장 2곳을 선정하여 방사성 모양으로 한 저가센서 및 LTE 통신을 기반으로 하는 모니터링망 을 구축하였다. 모니터링망 예비 운전 결과 주 오염원에 설치된 센서는 PM 측정값이 매우 높았고, 주 오염원에
서 떨어진 곳에 설치된 센서의 $\mathrm{PM}$ 측정값은 대부분 바 탕치에 근접하여 통상적인 먼지 확산 패턴을 나타낸 것 으로 보인다. 다만 주 오염원 인근에서의 순간 먼지 농 도 최고치가 매우 높아 이를 고농도 먼지 측정이 가능한 센서 개발 혹은 구매가 이루어져야 할 것으로 보인다. 또 한 모니터링 지점 외에서의 먼지 확산 추정을 위해서는 확산모델링을 이용하는 것이 효과적인데 이 때 현장의 기상 및 지형 조건 이외에도먼지 입도에 따른 거동을 반 영한 확산 모델식을 이용하는 것이 중요하다.

\section{사 사}

본 연구는 한국광해관리공단의 2021년도 광해방지기술 개발사업(먼지날림방지분야, 과제명: 미세먼지 저감을 위 한 광산환경 먼지날림 전주기 모니터링 시스템 개발)의 지원으로 수행되었다.

\section{References}

Aatos, S. (2003) Luonnonkivituotannon elinkaaren aikaiset ymparistovaikutukset (Environmental effects in natural stone production life cycle), Suomen ymparisto, Luonto ja luonnonvarat v.656, Ymparistoministerio. p.120-127.

Arup, O. \& Partners (1995) Environmental effects of dust from surface mineral workings: summary report and best practice guides, HMOS.

Abu-Allaban, M., Hamasha, S. and Gertler, A. (2006) Road dust resuspension in the vicinity of limestone quarries in jordan. J. Air Waste Manag Assoc., v.56, p.1440-1444. doi: 10.1080/ 10473289.2006.10464546

Appleton, T.J., Kingman, S.W., Lowndes, I.S. and Silvester, S.A. (2006) The development of a modeling strategy for thesimulation of fugitive dust emissions from in-pit quarrying activities: a UK case study. Int. J. Min. Reclam. Environ., v.20(1), p.57-82. doi: 10.1080/13895260500396404

Bluvshtein, N., Mahrer, Y., Sandler, A. and Rytwo, G. (2011) Evaluating the impact of a limestone quarry on suspended and accumulated dust. Atmos. Environ., v.45, p.1732-1739. doi: 10.1016/j.atmosenv.2010.12.055

British Occupational Hygiene Society Technology Committee (BOHSTC) (1985) Dustiness estimation methods for dry materials: Part 1, their uses and standardization: Part 2, towards a standard method, Science Reviews, Technical guide no. 4.

Charola, A.E. (1987) Acid Rain Effects on Stone Monuments, chem 1 supplement., p.436-437. doi: 10.1021/ed064p436

Cattle, S.R., Hemi, K., Pearson, G.L., and Sanderson, T. (2012) Distinguishing and characterizing point-source mining dust and diffuse-source dust deposits in a semi-arid district of eastern Australia. Aeolian Res., v.6, p.21-29. doi: 10.1016/j.aeolia.2012. 07.001

Chang, C.T., Chang, Y.M., Lin, W.Y. and Wu, M.C. (2010) Fugitive dust emission source profiles and assessment of selected control 
strategies for particulate matter at gravel processing sites in Taiwan, J. Air Waste Manage. Assoc., v.60, p.1262-1268. doi: 10.3155/1047-3289.60.10.1262

Chaulya, S.K., Chakraborty, M.K. and Singh, R.S. (2001) Air pollution modelling for a proposed limestone quarry. Water Air Soil Pollut., v.126, p.171-191. doi: 10.1023/A:1005279819145

Chakraborty, M.K., Ahmad, M., Singh, R.S., Pal, D., Bandopadhyay, C., and Chaulya, S.K. (2002) Determination of the emission rate from various opencast mining operations. Environ. Model Softw., v.17, p.467-480. doi: 10.1016/S1364-8152(02)00010-5

Higman, R.W. (1985) “Dustiness testing. A useful tool”, in Ventilation '85, in: Proceedings of the First International Symposium on Ventilation for Contaminant Control (code 10354), Toronto, Ont., Canada., p.693-702.

Hinds, W.C. (1999) Aerosol Technology: Properties, Behavior and Measurement of Airborne Particles, 2nd ed. Wiley-Intersci., p.15-53.

Holmes, N.S. and Morawska, L. (2006) A review of dispersion modelling and its application to the dispersion of particles: An overview of different dispersion models available. Atmos. Environ., v.40, p.5902-5928. doi: 10.1016/j.atmosenv.2006.06.003

IAQM (The Institute of Air Quality Management (2016) Guidance on the assessment of mineral dust impacts for planning, IAQM guidance report on mineral dust.

John, A.O. and Randolph Reed W.M. (2004) Characteristics of Fugitive Dust Generated from Unpaved Mine Haulage Roads. International Journal of Surface Mining. Int. J. Min. Reclam. Environ., p.236-252. doi: 10.1080/1389526042000263333

Joseph, G.M.D., Lowndes, I.S. and Hargreaves, D.M. (2018) A computational study of particulate emissions from Old Moor Quarry, UK. J. Wind Eng. Ind. Aerodyn., v.172, p.68-84. doi: 10.1016/j.jweia.2017.10.018

Lee, S.H. (2020) Review on Characteristics and Monitoring of Particulate Matter Emitted from Mining Operation. J. Korean Soc. Miner. Energy Resour., v.57, p.234-242. doi: 10.32390/ ksmer.2020.57.2.234

Lowndes, I.S., Silvester, S.A., Kingman, S.W. and Hargreaves, D.M. (2008) The application of an improved multi-scale computational modelling techniques to predict fugitive dust dispersion and deposition within and from surface mining operations, Proceedings of the 12th U.S./North American Mine Ventilation Symposium, K.G. Wallace ed., Reno, NV, ISBN 9780-615-20009-5. p.359-366.

Liu, Z., Wypych, P. and Cooper, P. (1999) Dust generation and air entrainment in bulk materials handling. A Review. Powder Handl. Process., v.11(4), p.421-425.

Lyons, C.P. and Mark, D. (1994) Development and Testing of a Procedure to Evaluate the Dustiness of Powders and Dusts in Industrial Use. HSE (62/1994).

Petavratzi, E., Kingman, S. and Lowndes, I. (2005) Particulates from mining operations: A review of sources. effects and regulations, Miner. Eng., v.18, p.1183-1199. doi: 10.1016/j.mineng.2005.06.017

Page, S.J., Volkwein, J.C., Baron, P.A. and Deye, G.J (2000) Particulate penetration of porous foam used as a low flow rate respirable dust size classifier. Appl. Occup. Environ. Hrg., v.15, p.561-568. doi: 10.1080/10473220050028385

Peng, X., Shi, G.L., Zheng, J., Liu, J.Y., Shi, X.R., Xu, J. and Feng, Y.C. (2016) Influence of quarry mining dust on PM2.5 in a city adjacent to a limestone quarry: Seasonal characteristics and source contributions. Sci. Total Environ., v.550, p.940-949. doi: 10.1016/j.scitotenv.2016.01.195

Petavratzi, E., Kingman, S.W. and Lowndes, I.S. (2007) Lowndes, Assessment of the dustiness and the dust liberation mechanisms of limestone quarry operations. Chem. Eng. Process, v.46, p.1412-1423. doi: 10.1016/j.cep.2006.11.005

Philip, A.B. and Michael, M.R. (1993) The Erosion of Carbonate Stone by Acid Rain: Laboratory and Field Investigations. J. Chem. Educ., p.104-108. doi: 10.1021/ed070p104

Reed, W.R. (2003) An improved model for prediction of $\mathrm{PM}_{10}$ from surface mining operations, Dissertation submitted to the faculty of the Virginia Polytechnic Institute and State University in partial fulfilment of the requirements for the degree of doctor in philosophy in mining and minerals engineering.

Schneider, T. and Hjemsted, K. (1996) Documentation of a dustiness drum test. Ann. Occup. Hyg. Soc., v.40, p.627-643. doi: 10.1093/ annhyg/40.6.627

Sumanth, C., Khare, M. and Shukla, K. (2020) Numerical modelling of PM10 dispersion in open-pit mines. doi: 10.1016/j.chemosphere. 2020.127454

Sethi, S.A. and Schneider, T. (1996) A gas fluidization dustiness tester. J. Aerosol Sci., v.27(1), p.S305-S306. doi: 10.1016/00218502(96)00225-X

Sairanen, M., Rine, M. and Selonen, O. (2018) A review of dust emission dispersions in rock aggregate and natural stone quarries. Int J Min Miner Eng., Int. J. Min. Reclam. Environ., p.196-220. doi: 10.1080/17480930.2016.1271385

Torno, S., Torano, J., Menendez, M. and Gent, M. (2011) CFD simulation of blasting dust for the design of physical barriers. Environ. Earth Sci., v.64 p.77-83. doi: 10.1007/s12665-010-0818-6

Torano, J., Torno, S., Diego, I., Menendez, M. and Gent, M. (2009) Dust emission calculations in open pit storage piles protected by means of barriers, CFD and experimental tests. Environ. Fluid Mech., v.9 p.493-507. doi: 10.1007/s10652-009-9136-5

US EPA (2004) AERMOD Deposition Algorithms - Science Document (Revised Draft) URL:https:/gaftp.epa.gov/Air/aqmg/ SCRAM/models/preferred/aermod/aer_scid.pdf

US EPA (2014) AP42: Compilation of Air Pollutant Emission Factors, Available at https:/www.epa.gov/air-emissions-factorsand-quantification/ap-42-compilation-air-emissionsfactors \#5thed (visited on 21/08/15)

US EPA (2004) AP42 section 11.19.2 Crushed stone processing and pulverized mineral processing, Available at https://www.epa.gov/ sites/default/files/2020-10/documents/c11s1902.pdf

US EPA (2004) AP42, Fifth Edition, Volume I Chapter 11: Mineral Products Industry. 11.19.2 Crushed Stone Processing and Pulverized Mineral Processing, Mineral Products Industry, 8/04, 5-7. (October 2015). Available at http://www.epa.gov/ttn/chief/ ap42/ch11/final/c11s1902.pdf.

US EPA (2004) URL: https:/gaftp.epa.gov/Air/aqmg/SCRAM/ models/preferred/aermod/aer_scid.pdf

World Health Organization (WHO) (1999) Hazard prevention and control in the work environment: Airborne Dust, World Health Organization, (WHO/SDE/OEH/99.14). doi: 10.1093/annhyg/ 44.5.405 